\title{
Overcoming the Modern Socio-Cultural Crisis - from Postmodern to Post-Postmodern: Theoretical Aspects
}

\author{
Tatyana Gumenyuk ${ }^{1, *}$, Mariana Palchynska ${ }^{2}$, Polina Herchanivska ${ }^{3}$, Yuriy Kozak ${ }^{4}$ and \\ Nataliia Kobyzhcha ${ }^{1}$
}

${ }^{1}$ Kyiv National University of Culture and Arts, Kyiv, Ukraine

${ }^{2}$ Odessa National Academy of Telecommunications n. a. O. S. Popov, Odesa, Ukraine

${ }^{3}$ National Academy of Culture and Arts Management, Kyiv, Ukraine

${ }^{4}$ Odessa National Economic University, Odesa, Ukraine

\begin{abstract}
The purpose of the article is to consider the negative aspects of postmodernism and study how post-post modernity can help humanity overcome the modern socio-cultural crisis. In their research, the authors used various scientific methods of cognition, such as analysis and synthesis, in particular meta-analysis and meta-synthesis, generalization, and induction.

The authors analyze the stages of development of civilization from the point of view of social progress, highlight their main characteristics and typological differences. The considered key points characteristic of postmodern, such as pluralism, negativism, relativism, denial of binarity in thinking, the extreme degree of nihilism, etc., lead to the understanding that the crisis that arose in the political, economic, socio-cultural life of society, at the turn of 2021 centuries, inherent in the very nature of postmodern. The values and perception of the postmodern are less and less consistent with the present time, and in its depths, a new worldview begins to crystallize, conventionally called postpostmodern, as a response to overcoming the current socio-cultural crisis. Post-postmodern, postmodern, like modern before them and similar phenomena are links of one chain, interconnected with each other and logically following from the processes of previous eras. The main components of the post-postmodern, which are formed from the problems of the postmodern, are highlighted and characterized.
\end{abstract}

As a result, the study showed that the currently being formed new worldview - post-postmodernity came close to the search for a new spirituality for the all-round development of a person and turning him into a socially mature being, as well as for resolving the internal contradictions of the postmodern worldview.

Keywords: Glocalization, postmodern, postpostmodern, trans-sentimentalism, virtualization.

\section{INTRODUCTION}

Postmodern, as a new worldview that emerged in the post-industrial society, in response to the crisis of ideas from previous eras, was rightfully considered a paradigm for the socio-cultural development of Western Europe and the world as a whole since the middle of the 20th century. Its formation and development ensured socio-cultural diversity, rejection of canons in culture, totalitarianism in thinking, the introduction of the principles of meritocracy into society's life, and pluralism becomes the leading philosophical trend, which ultimately made the world more democratic (Arribas-Bel, Kourtit, and Nijkamp 2013; Bashynska and Dyskina 2018; Jolley 2020). But by the beginning of the 21st century, changes are ripening in society, culture, in the spiritual world of a person and an understanding comes that postmodernism has exhausted its potential, unable to cope with comprehending the new reality, a socio-cultural crisis is

*Address correspondence to this author at the Kyiv National University of Culture and Arts, Kyiv, Ukraine; Tel: +38 (044) 2854403

E-mail: t.gumenyuk8@gmail.com brewing. Today, in various spheres of activity of modern society, a crisis can be traced: political, economic, raw materials, socio-cultural, anthropological, non-stop interethnic and geopolitical conflicts, the confrontation of Western-type cultures and Islamic fundamentalism, the growing gap between developed and developing countries, discrediting of such concepts like a family, marriage, environmental disasters, the dominance of mass culture, a decline in the quality of education, the flourishing and decline of a consumer society, which is being replaced by a society of experiences and other problems of our time pose serious questions to humanity (Stehr and Meja 2020; Jenkins 2021). The world is faced with pluralism, globalism, and freedom, brought to the point of absurdity, which began to be considered factors that increase social risk. Overcoming the current sociocultural crisis is essentially the problem of human survival in the modern world.

\section{LITERATURE REVIEW}

In their research, the authors used various scientific methods of cognition, such as analysis and synthesis, 


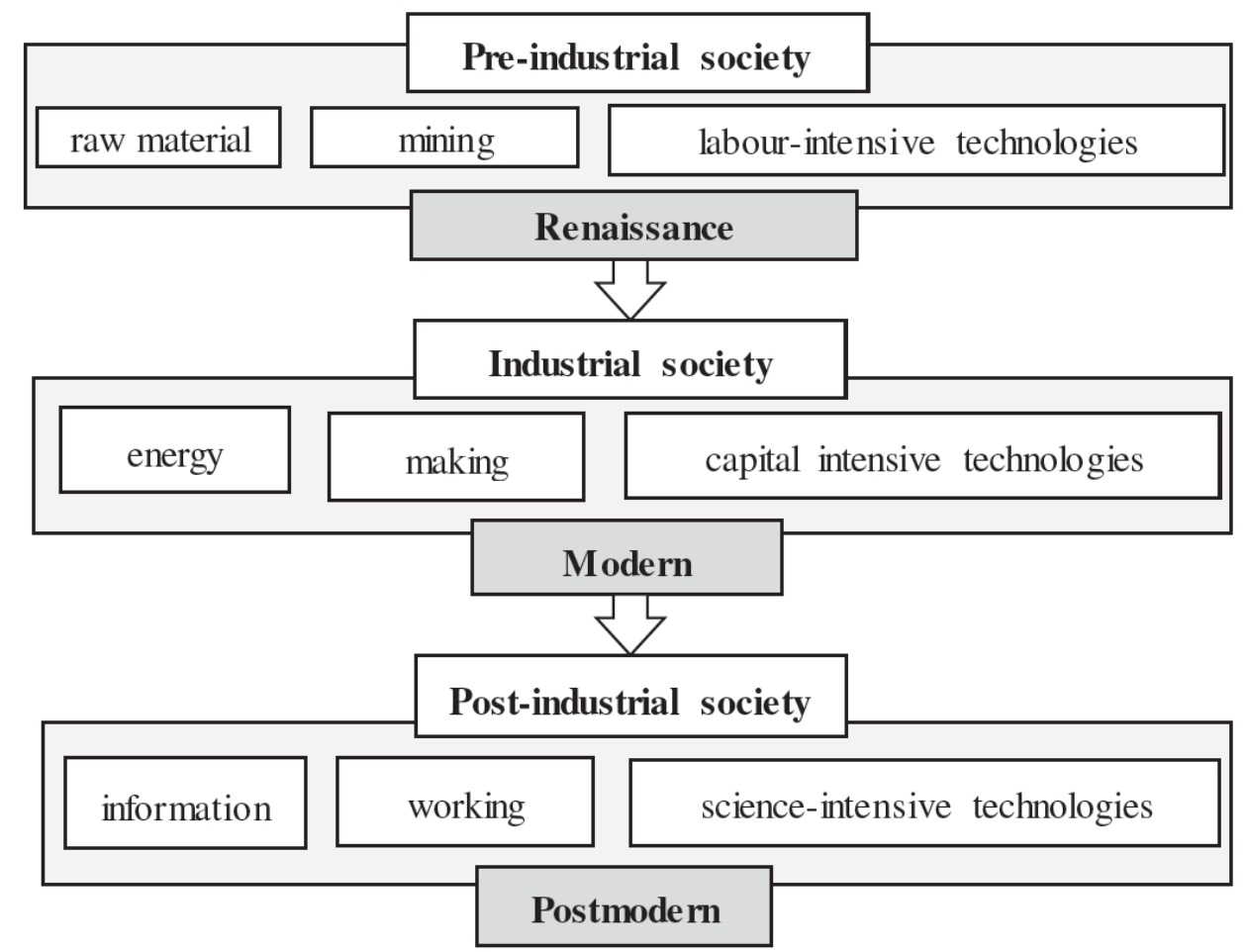

Figure 1: Stages of civilization development (based on Bell 1973).

in particular meta-analysis and meta-synthesis, generalization, and induction.

From the point of view of social progress, civilization, according to D. Bell's theory, went through three significant eras in its development: pre-industrial, industrial, and post-industrial, each of which is characterized by its socio-political system and socioeconomic relations, its worldview, and culture (Duff 1998). The stages of development of civilization according to the theory of D. Bell (1973) are clearly shown in Figure 1.

The industrial era, with its global socio-economic and political transformations associated with the industrial revolutions, which led to the replacement of manual labour with labour based on machine production, radically changes the worldview characteristic of the pre-industrial era, operating on the deep essence of human existence, paying close attention the inner world of a person with an inherent individuality, in which art was assigned an educational mission, where law and morality provided the opportunity for free moral choice, which did not abolish personal responsibility for their actions. The main idea of the new worldview, which replaced the Renaissance, characteristic of the pre-industrial era, was the belief in the unlimited possibility of the human mind in the discovery and cognition of the objective laws of the world order, which should serve historical progress and the possibility of reorganizing the world, which is achieved by rejecting the idea of the transcendent. This worldview, which arose from a combination of socioeconomic reasons, was called modern. Confidence in the progressive development of humanity, faith in continued progress, and unlimited possibilities of the human mind and will, which are capable of total submission of the world and its change, gave humanity atomic energy, quantum physics, electronics, the chemical industry, the theory of evolution and much more. In the ideas of modern, the priority of the present over the past and the future over the present is laid, the experience is denied, and only the present is recognized, and the present was considered as the foundation for further development, the ultimate goal of which is to build a happy future. The past was viewed as something that has outlived itself and is subject to replacement, and most often a radical replacement. Few people were interested in individuality, the spiritual world of a person, totalitarian states with a rigid state apparatus, and radical ideologies were created, which, creating a universal person, depersonalized him, which made it easy to manipulate him to achieve his goals.

The main tasks that were set before humanity in the modern era:

- $\quad$ reduce all the diversity of the surrounding reality to a single universal picture of the universe; 
- search and mastery by the human mind of absolute knowledge and laws about the universe;

- the desire to inscribe reality in the strict theoretical framework of absolute knowledge with the embodiment of this knowledge into existence, their use in the activities of humanity and the restructuring of the world by them;

- $\quad$ rejection of the idea of the transcendent;

development of universal norms of morality and law;

- $\quad$ achievement of the principles of centralism in the social, economic, and political life of society;

- building a happy future, which is the high purpose of a person.

Modernist ideas are inherently attractive and beautiful, but many of them are utopian, and some have led to the emergence of totalitarian states. The achievements of the human mind, in the absence of moral prohibitions, turn against a person, which ultimately led to two world wars, which marked the decline and decline of modern. Over two post-war decades, conditions for the structural restructuring of the economy with the transition to high-tech information and communication technologies are gradually beginning to form. Approximately, by the 60s of the twentieth century, the prerequisites for the change from the industrial era to the post-industrial one were realized. The evolution of eras has led to global changes in the socio-political, economic, and social organization of society and, as a consequence, the emergence of a new worldview as a reaction to the crisis of ideas from previous eras.

The post-industrial society is characterized by significantly accelerated development in a short time of social and economic processes. The variability of social conditions affects almost all spheres of human life from education to professional activity, from attitudes to lifestyle. Sociologist Z. Bauman characterizes the postindustrial era as "fluid modern" (Bauman 2000).

In the post-industrial era, a person is faced with new realities in socio-economic relations: more than half of the population is employed in the service sector communications, transport, trade, services, tourism, entertainment, the role of material production is decreasing, and the processes of reproduction, processing, and transmission of information are sharply increasing. In connection with this, the layer of intellectual workers is growing - scientific and technical specialists, professionals in the field of PR and advertising, managers. Humanity has realized that information is the most important strategic resource of the state along with raw materials and capital, and access to it is the most important condition for the country's socio-economic development. The social structure of society is also changing in connection with the disappearance of the class system and the transition to professional-corporate differentiation. The standard of living is increasing; the availability of education and quality medicine is growing. The principle of meritocracy is being implemented in society. Intangible values are beginning to come to the fore - work that brings a sense of inner satisfaction, impressive leisure, spiritual communication, problems of a healthy lifestyle.

The modernist worldview characteristic of an industrial society turns out to be outdated, unable to answer any questions that have arisen connected with the changed living conditions. First of all, art reacts to the new worldview, in which the mental specificity of the new era finds its visual embodiment, and at the same time art, itself becomes the generator of many of its ideas. Changes in socio-economic relations give an impetus to the emergence of innovations in culture, therefore, in the beginning, it is at the level of culture that a new trend emerges - postmodernism, gradually covering many spheres of social life, which leads to the emergence of a generalizing definition of the postindustrial era - postmodern, a term that has become widely applied in philosophical, sociological and economic works. The philosophical and theoretical origins of postmodernism were borrowed from the theoretical views of F. Nietzsche and S. Freud (Gemes 2001), poststructuralism, achievements in the field of natural science (the discovery of the divisibility of the atom, radioactivity, the creation of quantum mechanics, the concept of the big bang, the theory of relativity, the recognition and development of genetics, informatics), the theory of deconstruction. This is where diametrically opposite typological features of the two worldviews appear, presented in Figure 2. Comparing the main typological features of the two worldviews characteristic of the industrial and post-industrial eras is clear that the emergence of postmodernism is associated with criticism of the main provisions of modern.

Postmodern arose as a response to the destructive first and second world wars, infringement of human 


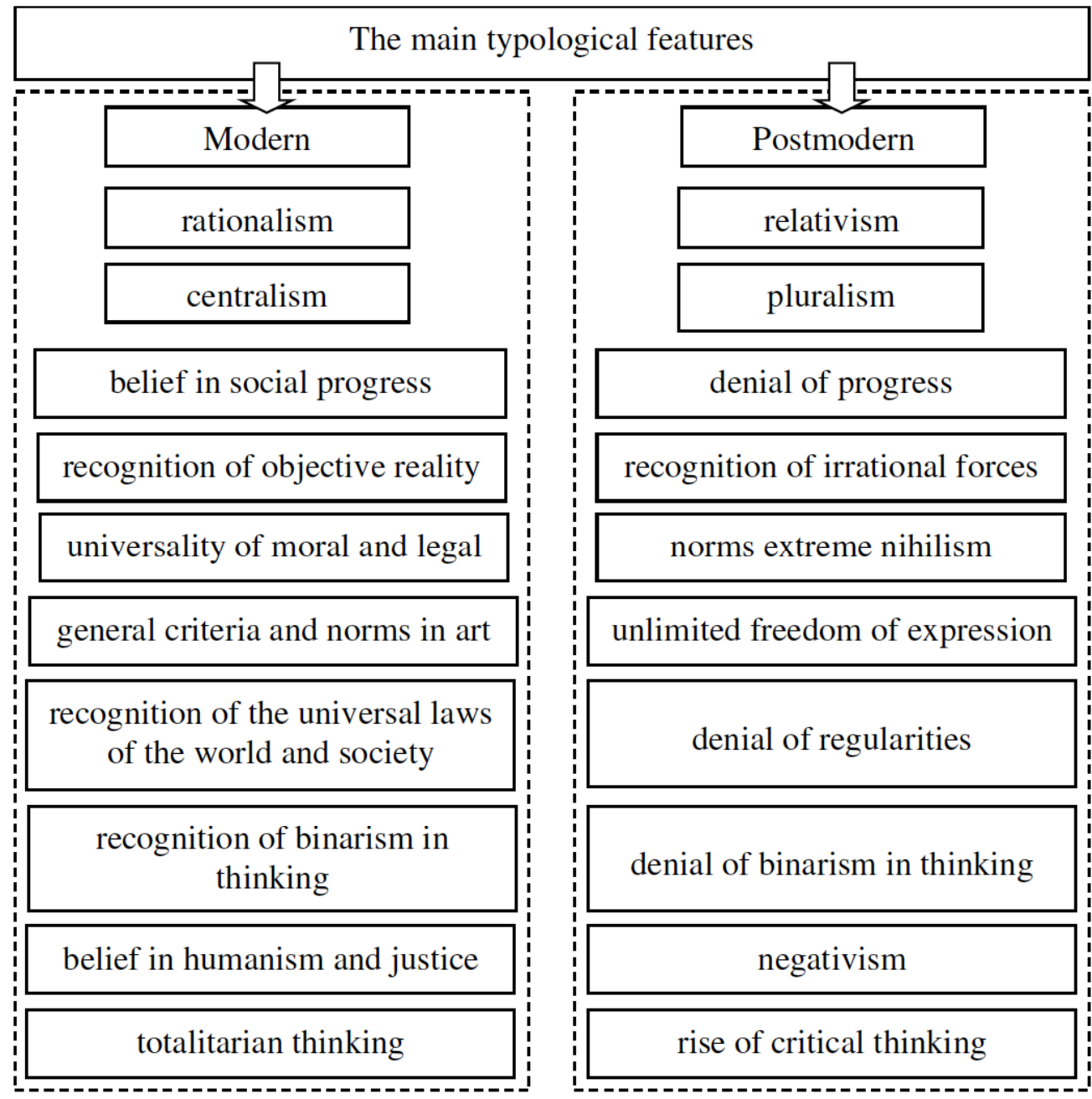

Figure 2: The main typological features of modern and postmodern.

rights, to authoritarian regimes and, in fact, was a rejection of the ideas of the Renaissance, realism, and modernism. A person ceases to be perceived as an unshakable, unchanging, static, and eternal sociohistorical entity, "the death of the subject" occurs. It is being replaced by an individual who is open to the perception of the new, ready for constant changes in his outlook and lifestyle.

Postmodern is characterized by the principle of relativism; therefore, everything is established, unchanging, associated with the universal laws of the development of society, the individual and culture, with centralism in the social, economic, and political life of society, in general, everything that fits the concepts of integrity, authoritarianism, absolutism, totalitarianism, unification unacceptably. Any hint of unity in the worldview, the position is perceived as violence, because everything in the world is relative and everything has the right to exist as an equal polysemy. Not recognizing authorities in philosophy and society, postmodern creates conditions for dialogue, uniting fields of knowledge that are not related to each other, which contributed to the emergence of new interdisciplinary scientific areas - artificial intelligence, global studies, synergetics, cosmology, and quantum mechanics. Postmodernism is hugely hostile to manifestations of a totalitarian way of thinking; therefore, at this time, critical thinking begins to flourish, when all and even one's own beliefs are questioned. Postmodernism rejects the concept of progress in social life; it is not possible, because the development of society is nonlinear, there is no past and future, but only the present. The possibility of a unified, systemic conceptual model of the universe is denied, it is declared untenable, due to the impotence of the human mind to understand the laws of the universe, the inability to get to the deep essence of things. The concept of truth as a principle of correspondence of knowledge to the objective state of the world is generally called into question since there is no universal criterion for truth. Truth is diverse, 
pluralistic, relative. Modern is characterized by a classical type of thinking through oppositions, such as subject-object, whole-part, internal-external, centerperiphery, masculine-feminine, high art - kitsch, i.e. the presence of a kind of binary code. Binary thinking makes it easier, more transparent, and more comfortable to understand the structure and laws of the surrounding reality. The new worldview, referring to the presence of pluralities in the surrounding world and in human relations, which, when interacting with each other, behave chaotically and illogically, do not allow distinguishing a organized opposition, as a result of which differences are no longer perceived, which means that binarism turns out to be invalid. Everything in the postmodern - science, philosophy, art - are in the marginality zone, preventing an individual from developing an exact position based on clear and transparent guidelines.

\section{METHODOLOGY}

The analysis of publications considering the modern processes of socio-cultural dynamics, the study of the works of postmodern ideologists Jean-Francois Lyotard (1984), Jean Baudrillard (1993), Umberto Eco (1995), Zygmunt Baumann (2000), and others, lead to the conclusion that the crisis that arose at the turn of the 20th and 21st centuries is inherent in the very nature of postmodern. The "new worldview" declared by the postmodern ideologists denied such universal concepts as truth, reason, being, the one, the absolute, progress, humanism, etc. Postmodern philosophy sharply criticizes all this, speaking from the positions of relativism and pluralism. Such a view with a passion for everything unstable, contradictory, fragmentary, and random cannot give clear individual guidelines in the surrounding reality.

Postmodernism recognized the individual world of a person as an absolute value, placing his interests and rights above the interests and rights of society. One of his most significant achievements was the recognition of the legitimacy of the existence of such essential realities for the individual as hobbies, everyday life, and leisure. In comparison with previous eras, a person becomes freer and more independent in the ways of self-expression and in the way of thinking. However, the fragmentation to which society was subjected to the individual, blurred the boundaries between good and evil, right and wrong, good and bad. In the sociocultural environment, which forms a set of such vital ideas for a person as the world around and interaction with it, finding one's place in it, developing moral guidelines and behavioural models, features of a deep crisis are also traced. Uncertainty and social tension are growing, and social contradictions are deepening. The new socio-cultural reality with a huge, regularly changing flow of information disorientated a person in the world around it. He loses the ability to critically perceive information, not having time to profoundly and comprehensively process and understand it, develop a clear position to various value concepts and phenomena, which forms superficial thinking, which means that the processes of creating identity itself and comprehending oneself as a person are disrupted. The radical implementation of the concept of pluralism, which implies the possibility of unlimited choice, in the absence of preferred coordinate systems, prevents the development of stable benchmarks, which, together with tolerance to different opinions and positions, leads to radical ideologies as one of the many socio-cultural paradigms in the mosaic world of postmodern. Disregard for traditions and their free interpretation, denial of the central idea, dominant values creates a feeling of chaos when everything is devoid of meaning and direction. Chaos is no longer viewed as a dangerous and undesirable state, on the contrary, the fragmentation of the whole to the status of chaos makes it possible to transform reality in the right direction, which increases the stability of the world system by reformatting the wrong political structures, which is reflected in the colour and flower revolutions that swept many countries, however, to stability did not lead, on the contrary, created centres of escalation. As a result, chaos is now perceived not as a factor giving impetus for development, but as a source of high social tension.

In the process of globalization, which is a characteristic feature of the modern world, there is an abrupt mixing of languages, customs, traditions, images and lifestyles. Games with reality led to the generation of ethical, religious, ideological, national mixes that pose a threat to national identity, which provoked resistance from large and influential social groups, which led to social tension and armed clashes. Multicultural eclecticism did not lead to the creation of a new unity but contributed to contradictions and conflicts.

The ideas of pluralism have found complete application in art, literature, in which the past heritage of humanity is taken from different eras, which has undergone deconstruction, leading to a shocking mixture of styles. All knowledge accumulated by the human society, cultural baggage is presented in the 
new worldview in the form of a mosaic consisting of fragments of heterogeneous traditions, styles and forms, united through ironic quotations, black humour, scepticism. Collage transforms from a private technique of artistic technique into a universal position for building culture. The rules for creating classical works are declared optional, and the artist's unlimited freedom of expression is being built into a cult. Comprehending postmodern creations requires the viewer to let them into their existence, leading to the creation of an active relationship between him and the work. The versatility of the methods of postmodern art makes it possible to include the entire palette of life phenomena, but also carries negative features, adjusting the criteria of art to the creative imagination of the creator, often leading to absurdity and the separation of contemporary art from reality. Modern trends in art, such as conceptualism, surrealism, pop art, etc., specific art practices - happening and performance, aroused a keen interest in the viewer, but the novelty has passed, and tiredness has accumulated from all destructive and confusing theories. The loss of classical aesthetic values, the closure within oneself, the blurring of the boundaries between the beautiful and the ugly, the sublime and the low in art has created the mass culture that we are observing at the present time, entailing disharmony and degradation of the individual's consciousness. In mass culture and mass society, the principles of unification and standardization are beginning to prevail, imposing on the world what postmodernism has always fought against.

\section{RESULT \& DISCUSSION}

The transformations that have affected society, man, culture, lead to new questions to which the postmodern is no longer able to give answers, its crisis is brewing, and a new ideology is ripening in the depths of its worldview, conventionally called postpostmodern. Post-postmodern, postmodern, like modern before them, and similar phenomena appear at specific periods of history as a social protest against the existing worldview, but each of them is connected with each other, prepares, matures and logically follows from the processes of previous eras. Figure 3 shows the main components of post-postmodern, which are formed from the problems of postmodern.

Globalization is an objective process aimed at unification and integration into a single world system of political, economic, scientific, technical and cultural spheres of human activity. Unification presupposes the introduction of uniform standards in such an important area for the individual as culture, the task of which has always been to form continuity, self-awareness and identity with their national roots. The urgent issue of the destruction of cultures and the identity of peoples gave rise to such a phenomenon as glocalization, which allows maintaining social uniqueness within the

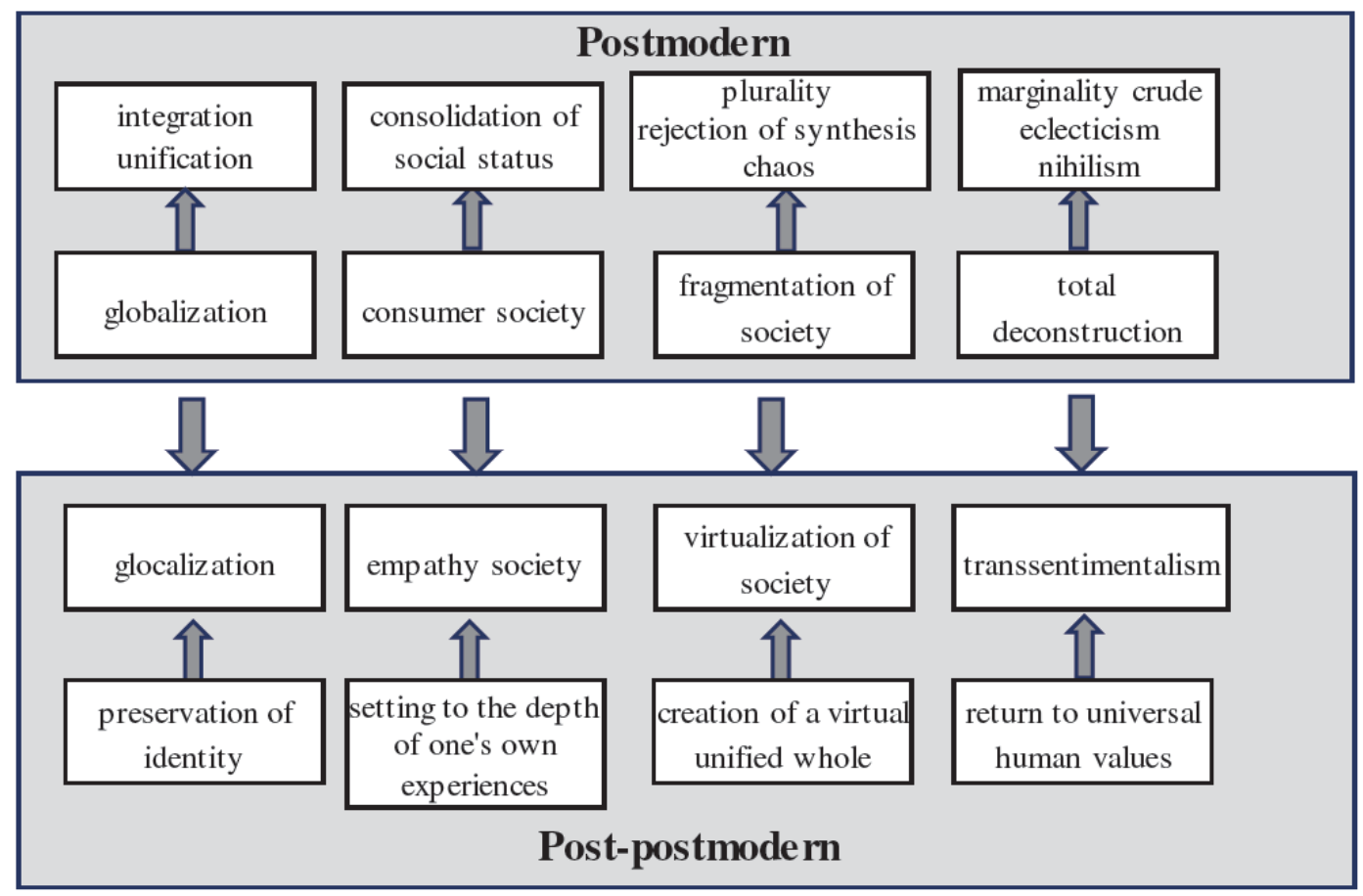

Figure 3: The main components of the emerging post-postmodern. 
framework of the global social space. Postmodern has declared the individual world of a person as an absolute value, post-postmodern translates this to the level of societies. Globalization allows, thanks to the presence of a shared information network, to master the richest heritage of the culture of humanity, and glocalization - to preserve its originality among all the diversity. An example is such countries as South Korea, Japan, Singapore, Hong Kong, etc., which are part of the global system and at the same time preserve their culture and identity. Real changes are also taking place in society. A consumer society in which things solved both functional tasks and nonfunctional ones, focused mainly on the assertion and consolidation of social status through the possession of specific material values, be it a house, in a prestigious area, a yacht, an expensive car, a picture of a fashionable artist, and even exclusive hours, etc., gives way to a society of a new motivational type - a society of experiences, in which these motivations do not play a significant role, and an attitude with a focus on intensifying one's current life with the help of emotionally coloured impressions acquires significance. This inner orientation is reflected in the "boom in loans", in the motives for starting a family, in the choice of education, planning recreation and leisure.

The structural ordering and integrity of society in the past was replaced in the postmodern worldview by a plurality, consisting of separate, scattered and unrelated fragments, and within the post-postmodern, information and telecommunication technologies that have been rapidly developing in recent decades have turned the world into a "one big village", linking them into virtual space into a single whole the most remote places of the globe. A new criterion for the differentiation of society by inclusion or non-inclusion in virtual social communities is emerging. The powerful influence of information technology on society in all its dimensions is now generally recognized. In the virtual world, people satisfy their most diverse needs: communication, informational, entertainment, socializing, find opportunities for self-expression. The virtual world allows an individual to be free in the process of communication, carrying out interpersonal interaction in real-time instantly, according to the principle of "here and now", helps to create contacts for establishing and running a business, exchange information (photo, video, audio materials), find likeminded people and lead active discussions on topics of interest, organize interest groups, comment and express their opinions on various events taking place in society, but also contributes to the blurring of the border between objectively existing and imaginary, leading to a break with reality. The game model of being inherent in postmodern is absolutized in postpostmodern, leading to a change in reality in practice, which we observed in protest moods, "revolutions" that arose not without the help of computer technology due to the manipulation of public consciousness, in several countries in North Africa and the Middle East, in Russia, Serbia, Georgia, Kyrgyzstan, etc.

When immersed in the virtual world, the processes of forming abstract and logical thinking are disrupted, which can be realized under the influence of a written text, by mentally creating specific images. A modern person gradually loses this ability to think consistently, logically, independently, since he receives the bulk of information in a screen format in the form of specific ready-made visual images, pictures, symbols that do not require thinking and reflecting about what he has seen, losing the ability to critical thinking. Such an individual becomes easily manipulated, dependent, perceiving the information offered to him in the screen format as the only truth that does not need to be comprehended and confirmed.

In the post-postmodern worldview, transcendentalism is formed and consolidated, as a response to the fatigue of humanity from allencompassing deconstruction, irony, stylization, relativism, nihilism, superficiality, uncertainty and multi variance, thoughtless consumerism and postmodern hedonism. A revival of general classical concepts and universal truths begins, while not constrained by ideological foundations. Unlike postmodern, belief in bright future returns, to universal, enduring, eternal values that reduce the feeling of risk in everyday life. Nostalgia for a high style in literature, art, a return to the consideration of religious concepts, the search for depth and spirituality is seen as a transition to neoromanticism and neo-realism.

\section{CONCLUSION}

Like any phenomenon, postmodern has embodied the positive and negative sides. It destroyed many obsolete and hindering progress sides and elements of previous eras and is currently in a state of transition to a new worldview. The 21 st century, having opened a new era in the development of society and culture has led humanity to the need to rethink the values of postmodern and to the formation of a new worldview 
that can explain and provide answers to the mass of accumulated problems in all spheres of society. The main issues that have arisen today are the inability of postmodern to create stable models of identification, leading to a person's unawareness of his place in the world, difficulties in adapting to the accelerated pace of life that is falling on him, to information growing exponentially, to a senseless search for landmarks in their absence, to the extremes of relativism, when "everything will fit, and everything is allowed", which often leads to disorientation, maladjustment, psychological stress, therefore E. Giddens and U. Beck characterized the post-industrial society as a "risk society" (Beck 1992). In the socio-political aspect, the absence of a general idea led to passivity, noninterference in the course of history. Postmodernism, which has rejected everything universal for so long, cannot reject universal human values, such as belief in better and just order, in moral perfection, in the great mission of enlightenment, in the right to a dignified, peaceful life.

The new worldview that is currently being formed post-postmodern came close to the search for a new spirituality for the all-round development of a person and turning him into a socially mature being, as well as for resolving the internal contradictions of the postmodern worldview.

\section{REFERENCES}

Arribas-Bel, D., Kourtit, K., Nijkamp, P. (2013). Socio-Cultural Diversity and Urban Buzz. SSRN Electronic Journal. https://doi.org/10.2139/ssrn.2306499
Bashynska, I., and Dyskina, A. (2018). The overview-analytical document of the international experience of building smart city. Business: Theory and Practice. 19. 228-241. https://doi.org/10.3846/btp.2018.23

Baudrillard, J. (1993). Symbolic Exchange and Death (Theory, Culture \& Society). Sage Publications. 254.

Bauman, Z. (2000). Liquid Modernity, Oxford, United Kingdom: Polity Press, 240.

Beck, U. (1992). Risk Society: Towards a New Modernity, London, United Kingdom: Sage Publications Ltd., 272.

Bell, D. (1973). The Coming of Post-Industrial Society: A Venture in Social Forecasting. New York: Basic Books, 618.

Duff, A. (1998). Daniel Bell's Theory of the Information Society, Acoustics, Speech, and Signal Processing Newsletter, IEEE. 24(6). 373-393 https://doi.org/10.1177/0165551984232379

Eco, U. (1995). Apocalyptic and integrated intellectuals: mass communications and theories of mass culture, In book: Apocalypse postponed,. 17-35.

Gemes, K. (2001) Postmodernism's Use and Abuse of Nietzsche. Philosophy and Phenomenological Research.; 62(2). 337360.

https://doi.org/10.2307/2653702

Jenkins, P. (2021). The Postmodern Era, In book: Understanding Mental Health and Mental IIIness. https://doi.org/10.4324/9780429440526-9

Jolley, J. (2020). Embodying Plurality: Becoming more-than homeless. Transactions of the Institute of British Geographers. 45(3). https://doi.org/10.1111/tran.12373

Lyotard, J.-F. (1984). The Postmodern Condition: A Report on Knowledge, Manchester, United Kingdom: Manchester University Press. 136.

Stehr, N., and Meja, V. (2020). Modern societies as knowledge societies In book: New Horizons in Sociological Theory and Research. https://doi.org/10.4324/9781003073284-6

Received on 27-02-2021 Accepted on 31-03-2021 Published on 06-04-2021

https://doi.org/10.6000/1929-4409.2021.10.88

(C) 2021 Gumenyuk et al.; Licensee Lifescience Global.

This is an open access article licensed under the terms of the Creative Commons Attribution Non-Commercial License (http://creativecommons.org/licenses/by-nc/3.0/) which permits unrestricted, non-commercial use, distribution and reproduction in any medium, provided the work is properly cited. 